\title{
Automated Drug Delivery in Anesthesia
}

\author{
Martine M. Neckebroek • Tom De Smet • \\ Michel M. R. F. Struys
}

Published online: 13 December 2012

(C) Springer Science + Business Media New York 2012

\begin{abstract}
Automated drug administration by closed-loop systems has been proposed to optimize drug administration during anesthesia and sedation. Closed-loop systems are able to make decision on their own and try to reach and maintain a preset target. This review describes the milestones and recent development in automated drug delivery systems applicable during sedation, anesthesia and postoperative pain relief.
\end{abstract}

Keywords Target-controlled infusion - Closed-loop · Propofol - Bayesian optimization · Automated drug administration · PID

\section{Introduction}

Changes in techniques and patient populations make it more challenging than ever to manage anesthesia in a fast, simple and safe way. A wide spectrum of pharmacological

M. M. Neckebroek

Department of Anesthesia, University Hospital Ghent,

De Pintelaan 185, 9000 Ghent, Belgium

e-mail: martine.neckebroek@ugent.be

T. De Smet

Demed Medical Engineering, Hollebeek 145, 9140 Temse,

Belgium

e-mail: tds@demed.be

M. M. R. F. Struys ( $\square)$

Department of Anesthesiology, University Medical Center

Groningen, University of Groningen, Hanzeplein 1, 9700 RB

Groningen, The Netherlands

e-mail: m.m.r.f.struys@umcg.nl

M. M. R. F. Struys

Ghent University, Ghent, Belgium actions (analgesia, hypnosis, and suppression of somatic and autonomic responses to noxious stimuli) are needed to control the general anesthetic state [1]. During general anesthesia, opiates are classically applied to manage the nociception-antinoception balance, and short acting hypnotics are widely used to titrate the hypnotic component of anesthesia.

The ultimate goal when administering a particular dose of an anesthetic or analgesic drug is to obtain the desired clinical effect, for which a specific therapeutic concentration of the drug at the site of action (=the receptor) is required. At the same moment, the clinician wants to avoid side effects in order to reach the highest standards of care.

In the world of control engineering, dealing with the behavior of dynamic systems, closed-loop control can be defined as the management of single- or multiple-output variables of a system following a specific target value, whereby a controller adapts the system's inputs to reach and maintain a desired effect on the output. The goal of a closed-loop controller is to calculate solutions for an accurate corrective action from the controller that result in system stability, that is, the system will hold the set point and not oscillate around it [2]. Extrapolated to the world of anesthesia, this means that any action to maintain a specific pharmacological effect can be called a closed-loop control. Even a manual titration of drug infusion by a clinician is a closed-loop action as the clinician continuously monitors and adapts his/her actions. However, the clinician serves as the "human controller" in the loop, and as a consequence the control actions are intermittent and irregular in time [3•]. Computer-based closed-loop administration requires various system components : (1) a controlled variable representative for the targeted therapeutic effect; (2) a clinically relevant set-point or target value for this variable; (3) a control actuator, which is, in this case, the infusion 
pump driving the drug; (4) a system, in this case a patient; (5) an accurate, stable control algorithm [4]. Various closed-loop systems exist to control various steps in the dose-response relationship. When a system is able to control a specific set dose or drug concentration, it can be called a pharmacokinetic closed-loop controller. When a specific therapeutic effect is targeted, the control system is defined as a pharmacodynamic closed-loop system.

\section{Pharmacokinetic Closed-Loop Systems in Anesthesia}

Expired concentration of various drugs can be measured continuously. For the inhaled anesthetics such as desflurane, sevoflurane, and isoflurane, this can be done clinically using the spectrometric gas analyzers available in most of the anesthesia monitors. Using these inhaled anesthetic concentrations, a closed-loop system can be applied targeting a specific inspired or end-tidal concentration. Over the last decades, various experimental control systems were developed [5, 6]. More recently, a commercial closed-circuit anesthesia ventilator (Zeus ${ }^{\circledR}$, Dräger Medical, Lübeck, Germany) was released. This machine is able to target the end-tidal concentrations of inhaled anesthetics and to control the fresh gas flow using closed-loop technology [7].

Recently, experimental devices measuring exhaled concentration from intravenously given propofol have been tested using proton transfer mass spectrometry and headspace solid-phase microextraction coupled with gas chromatography-mass spectrometry (HS-SPME-GC-MS) [8] or ion mobility spectrometry coupled to a multicapillary column for pre-separation (MCC-IMS). Grossherr et al. [9] used gas chromatography mass spectrometry to measure exhaled propofol. Until today, propofol exhaled concentration measures are still experimental and no closed-loop systems have been developed using this concentration as the controlled variable.

\section{Pharmacokinetic-Dynamic Closed-Loop Systems}

\section{The Controlled Variable}

The accuracy of closed-loop controlled drug administration strongly depends on the robustness and reliability of the controlled variable. Various drug actions can be measured directly using physiological measures. Examples are heart rate, respiration, blood pressure, and neuromuscular blockade. Various research groups have used direct measures to steer the feedback from controlled administration of cardiovascular drugs, anesthetics and muscular blocking agents. Some of these systems, such as the IVAC Titrator (Carefusion, San Diego, CA, USA) controlling nitroprusside using blood pressure as controlled variable, had been commercially available in the past but were discontinued. In contrast to these direct measures, surrogate measures are required to observe the hypnotic component of anesthesia or the balance between nociception and antinociception. However, they have to be interpreted with caution as a full correlation with all levels of drug effect might be missing.

Various surrogate measures have been studied to observe hypnotic drug effects. Both the spontaneous and evoked electro-encephalogram (EEG) have been proven to accurately measure cerebral hypnotic drug effects and be good candidate controlled variables closed-loop of hypnosis. Early closed-loop systems used computerized EEG derivatives like spectral edge frequency (SEF) and median frequency (MEF) [10]. More recently, the bispectral index $\left(\right.$ BIS $^{\odot}$, Covidien, Boulder, CO, USA) has been used as controlled variable in multiple studies. BIS has been designed using multivariate statistical analysis, to combine multiple EEG features, including higher-order spectra and phase correlations between spectra into a more accurate indicator. Aside from BIS, State and Response Entropy (M-entropy, GE Healthcare, Helsinki, Finland), two spectral entropy parameters based on the irregularity in the EEG have been used recently to measure hypnotic drug effect during closed-loop administration [11-13•]. One research group has tested auditory evoked potentials, more specific the mid-latency auditory evoked potential (MLAEP) as controlled variable for closed-loop control of propofol administration $[14,15]$. One of the major challenges when using a surrogate measure is the delay in the system, which adds complexity to the controller. All currently available indices have different time lags to react to a change in the level of anesthesia. Pilge and coworkers compared the time lag in three commercially available computerized EEG systems by using an artificial EEG signal and found time variable delays between 14 and $155 \mathrm{~s} \mathrm{[16].}$

Closed-loop administration of analgesics have been challenging because controlling the balance between nociception and antinociception is a difficult task. Liu et al. [13•] have used EEG to co-administer propofol and opioids, however, the inclusion of a real "analgesia index" in closedloop is still lacking. Using the difference between response (RE) and state (SE) entropy derived from the EEG as a measure of frontal electromyographic (FEMG) activity, Mathews and coworkers found that remifentanil may be delivered using an algorithm that maintains the difference between RE and SE between the upper and lower boundary condition [17], however, this has not been incorporated in a closed-loop system. More recently, the same authors found that the Composite Variability Index (CVI), based on the variability in BIS and FEMG activity, might be useful to predict movement during anesthesia, which can be controlled by administering analgesics $[18 \bullet \bullet]$. 
The Target Value

The target value or set-point is the value set by the clinician and will be approached as closely as possible during the maintenance of anesthesia. A clinically adequate individual target is essential for the accuracy of the closed-loop system. Two types of set-points can be used: (1) set-points that are based on population mean data, or (2) individual data measured at the start or just before the control period. The latter type could be expected to more closely correspond to the clinical needs during the course of a surgical procedure [19].

\section{Control Methods}

Multiple control methods have been used to guide closedloop anesthesia. Although on-off control was used in the early days, severe oscillation due to the complexity of drug behavior have limited this approach [20-24]. ProportionalIntegral-Derivative (PID) control has also been used in various anesthesia-related closed-loop applications.

A PID controller is based on a straightforward mathematical derivative of the observed error, and can be written as:

$$
\mathrm{dR} / \mathrm{dt}=K_{\mathrm{P}} * d(\text { err }) / \mathrm{dt}+\operatorname{err} / K_{\mathrm{I}}+K_{\mathrm{D}} * d^{2}(\text { err }) / d^{2} t
$$

with err, being the error between the target and the observed value, causing a response $R$ in the actuator. The constants $K_{\mathrm{P}}, K_{\mathrm{I}}, K_{\mathrm{D}}$ are tuned by calculations from models of the system, by computer simulations, or derived from trials using tuning rules [25]. PID controllers have been applied under well-controlled situation after fine-tuning of the constants [26-29]. However, the use of a general PID controller to control the complex dose-response relationship when administering drugs (with $R$ being the administration rate), could be slow in establishing control and may cause oscillations.

The complexity of the dose-response relationship can be decreased by implementing knowledge of the pharmacokinetic-dynamic behavior of the drug. Incorporating pharmacokinetic-dynamic models will enable a controller to use a specific plasma or effect-site concentration as $R$ (see formula 1) instead of a dosing rate. The use of plasma or effect-site targeted drug administration is well understood and will lower the order of complexity of the resulting system [30]. Nowadays, the use of modern powerful microprocessors may allow better control through the incorporation of more sophisticated models describing the dose-response relationship, or by reverting to other control algorithms like MPC or fuzzy logic [31, 32].

Closed-loop control might benefit from adaptive finetuning. Various theoretical approaches can be used to adapt the control parameters toward the behavior characteristics of a specific individual. Examples are state estimation, mixed-effects pharmacokinetic or dynamic modeling using Bayesian estimation [33• 34], Kalman filtering [35], fuzzy logic [31, 36] or other engineering techniques such as neural network applications [37] and reinforced learning [38, 39]. Bayesian optimization, as proposed by Sheiner and coworkers [40], individualizes the pharmacodynamic relationship by combining individual information with the knowledge of an a priori probability density function containing the statistical properties of the parameter to be estimated [41]. The Bayesian method starts from a standard, population-based response model providing the prior distribution of parameter values. These values are adjusted to reflect the patient's own parameters over time, based on the observed response of the individual patient under varying circumstances [42]. The Kalman filter will apply a recursive method to calculate numbers for a given doseresponse relationship for the specific patient, for example to individualize the constant for plasma-effect site equilibration [43, 44]. Fuzzy logic control is based on fuzzy set theory as proposed by Zadeh [45] in the sixties. An approach of model adaptation based on fuzzy logic was proposed by Kern and coworkers [46]. Recently, Moore and Doufas used reinforcement learning to control propofol closed-loop administration in a simulated environment. Reinforcement learning (RL) is an intelligent control method with an excellent record of success in difficult robotic control tasks. This method is based on a mathematically structured framework for goal-directed decisionmaking and is suitable for biological applications that are characterized by an inherent time delay between control actions and effects [38, 39].

\section{Examples of Closed-Loop Drug Administration}

Human-operated drug administration can be considered as a form of closed-loop control. Various patient-controlled drug administration systems are available to deliver individualized dosages of analgesics and hypnotics. This technology, called patient controlled analgesia (PCA) or patient-controlled sedation (PCS) systems, offers the possibility to set a continuous background infusion and to allow patients to administer themselves additional top-up dosages. PCA without background infusion is also used. Post-operative PCA usage has been described for analgesics such as morphine, piritramide, fantanyl, tramadol, and others [47-51]. In a systematic review, Walder and colleagues showed that the some evidence exists that in the postoperative pain setting, PCA with opioids, compared with conventional opioid treatment, improves analgesia and decreases the risk of pulmonary complications, and that patients prefer this option [52]. The development of 
advanced drug delivery devices that offer lock-out times and total amount of drug delivery per time is required. Strict hospital guidelines are required avoid drug overdose, causing potentially life-threatening side effects such as respiratory depression [53]. Recently, the feasibility of the use of intravenously delivered remifentanil during labor by PCA, under strict observation, has been demonstrated [54-59]. Large randomized controlled trials are required to prove that this technique can become an alternative for epidural analgesia during labor [60•]. PCS might offer comfort and anxiolysis during therapeutic procedures such as endoscopy. Various experimental devices for propofol PCS administration have been designed in the past [61-63], some of these even adding TCI technology into the system to optimize drug delivery [64-67]. Doufas and colleagues tested an automatic response test to optimize propofol administration for conscious sedation and showed that failure to respond to automated responsiveness monitoring precedes potentially serious adverse effects of sedation such as loss of responsiveness, and that the monitor was not susceptible to false-positive responses [68-70•]. An enlarged commercial version of this device, called Sedasys ${ }^{\circledR}$ (Ethicon Endo-Surgery, Cincinnati, OH, USA) has been tested in two studies. The system incorporates the automated responsiveness monitoring and in-built capnography and pulse oximetry. If responses to stimuli are inadequate, the increase in infusion rate is limited; whereas if apnea or hemoglobin oxygen desaturation is detected, then the infusion is stopped and additional oxygen administered. After a successful feasibility study [71], the system was then used in a large randomized study of sedation during upper gastrointestinal endoscopy and colonoscopy, and found to be associated with a reduced incidence of adverse events compared with standard care (5.8 vs $8.7 \%$ respectively) [72•].

When feeding a continuously measured drug effect back to the drug delivery device, fully automated drug delivery will be enabled. The clinician has only to set a specific target value to be reached and maintained. Early perioperative closed-loop technology focussed on the administration of cardiovascular drugs and neuromuscular blocking agents. For example, Kenny and coworkers [73] successfully evaluated closed-loop control of arterial pressure using a mixture of trimetaphan camsylate and sodium nitroprusside during controlled hypotensive anesthesia for local resections of intraocular melanoma. In the 1980s-1990s, various researchers tested the accuracy of closed-loop controlled administration of atracurium [36, 74] and vecuronium [75]. Due to the commercialisation of the reversal drug suggamadex, interest in closed-loop administration of muscle relaxants has declined.

Early developed closed-loop system used hemodynamic alterations to guide hypnotic drug delivery, due to a lack of availability of reliable cerebral drug effect monitors, such as $\operatorname{EEG~[21,~22,~31].~The~commercialisation~of~more~}$ accurate cerebral effect measures enabled the development of EEG based closed-loop delivery of hypnotic-anesthetic drugs. Schwilden and Schüttler pioneered closed-loop administration of methohexital [76], propofol [77] and even alfentanil [78] using the EEG median frequency as controlled variable and an adaptive controller based on pharmacological principles, whereby adaptation in the pharmacokinetic part was applied. Kenny and coworkers developed a proportional-integral (PI) based closed-loop system for propofol administration using a mid-latency evoked potential derived index (AEPindex) as the controlled variable. The input variable was the predicted plasma concentration of propofol. As explained earlier in this chapter, concepts of TCI were applied to decrease the complexity of the PI controller. Accurate control was observed in most of the patients [14].

Most of the recent developed hypnotic closed-loop systems are guided by the EEG-derived bispectral index or BIS. Sakai and colleagues used an early version of the BIS and concluded that their closed-loop system provided intraoperative hemodynamic stability and a prompt recovery from sedative-hypnotic effects of propofol [79]. Absalom and Kenny proposed propofol closed-loop delivery using BIS and PID control of a plasma controlled TCI system and revealed acceptable control during major orthopedic surgery [30] and during sedation [80]. Although these researchers improved the performance of their control system by implementing more advanced effect-site targeted TCI, they also concluded that the PID controller might still face some stability problems. A similar BISguided propofol closed-loop system using a control system described as a proportional-derivative (PD) control to steer a specific effect-site concentration was developed by Liu and coworkers. Their system was tested during anesthesia and resulted in lower propofol consumption, longer induction time but with better hemodynamic stability, less excessive anesthetic levels (BIS $<40$ ), similar hemodynamic stability and faster recovery $[81,82]$. More recently, Liu tested a more advanced version of their BIS-guided system, now claiming full PID control, for closed-loop coadministration of both propofol and remifentanil. On top of the PID controller, the authors describe a rule-based algorithm that determines when to change the propofol or remifentanil targets. This system showed a better overall performance compared to manual administration in a multicenter study [83•]. A similar approach was used with an alternative EEG-derived index, spectral entropy [13•]. Recently, Liu fully explained his control system in a response to a letter to the editor of Anesthesiology. In this letter, Looke criticized the approach by Liu and coworkers by stating that the system should not be described as a PID 
controller, but as an empirically derived expert system controller. This author stressed on the importance of using a multidisciplinary team approach, including both medical and control engineering professionals when developing closed-loop systems, and stressed also on the application of simulation studies before entering into clinical practice. In their reply, Liu and coworkers revealed in great detail the structure of their algorithm and PID properties are certainly recognized. They also debated on the utility of simulation studies during closed-loop development [84•].

As said previously, automated drug delivery could benefit from the implementation of principles of pharmacokinetics and dynamics in the control algorithm. A BIS-guided, patient-individualized, model-based adaptive control system was developed and tested by Struys and De Smet during sedation and general anesthesia $[85,86]$. The controller is based on a pharmacodynamic model represented by a sigmoidal $E_{\max }$ model. Initially, the initial patient-specific pharmacodynamic profile is calculated automatically during induction by correlating all predicted effect-site concentrations with the corresponding BIS value. During closed-loop control, the controller minimizes the difference between measured and desired effect by using the pharmacodynamic model [86]. The authors compared this closed-loop controlled administration of propofol versus standard practice controlled administration and concluded that closed-loop control was clinically acceptable. In an accompanying editorial, Glass and Rampil [87] questioned whether the controller could become clinically acceptable outside the study population, because all subsequent adjustments were based on a static pharmacodynamic curve and only BIS of 50 was targeted in combination with continuous infusion of propofol or spinal anesthesia. As it might be considered unethical to stress the controller under extreme conditions outside the ranges of good clinical practice, a simulation study was undertaken and proved that even under extreme conditions, the model-based controller exhibited no behaviour problems and performed better than a previously published PID controlled closed-loop system [88]. As the original controller assumed a drug-free patient and used a fixed pharmacodynamic curve individualized during induction, De Smet and Struys included Bayesian optimization (as explained earlier in this article) into the original modelbased controller to overcome these shortcomings (Fig. 1). They estimated the optimal modelling weights for this Bayesian-based BIS guided closed-loop system for propofol administration in a large simulation study, hereby stating that this system was safe enough to be introduced into clinical testing [34]. This accuracy and clinical feasibility was tested in a clinical study guiding propofol administration during anesthesia for ambulatory gynaecological procedures. They proved that the system performed better that BIS-guided, effect compartment controlled propofol administration titrated by the anaesthesiologist [33•].

Closed-loop systems have been developed for a BISguided isoflurane administration using a controller with a cascade structure, originally described by Gentilini et al. $[89,90]$. Recently, Moore and Doufas designed a closedloop system using an intelligent system technique called "reinforcement learning", for achieving optimal control in systems characterized by noise, nonlinearity, inherent time delays, and uncertainty [38, 39]. This system has not been tested in clinical practice.

Most of the above mentioned controllers are without a predictive forecasting horizon. Recently, Ionescu et al. described a model-based predictive control strategy, which is more advanced and might form the basis for future innovative engineering. Specifically, these authors were able to show that adaptive model update of the patient's pharmaco-dynamic profile is possible, allowing detection of significant variable time-delays in the patient's response to drug infusion and presence of artefacts in ICU [91].

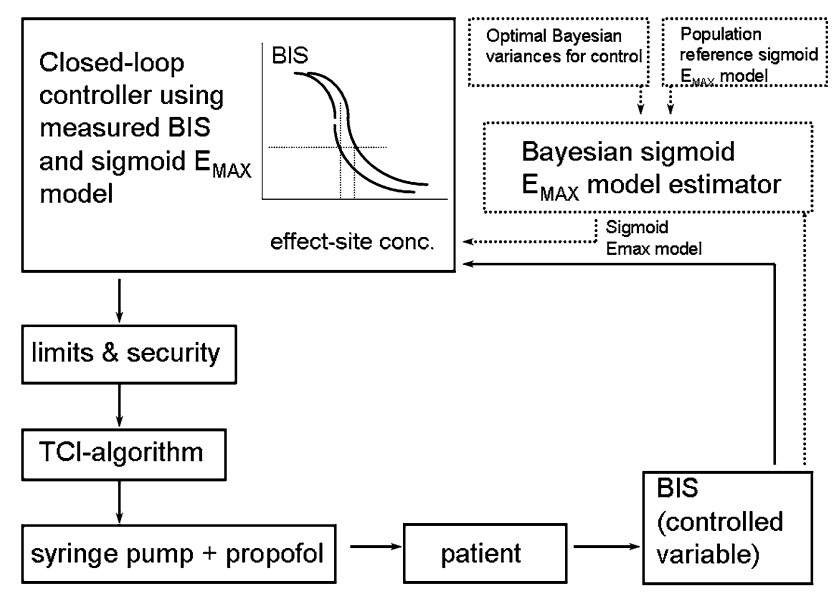

Fig. 1 Flow chart of the closed-loop system. The straight lines represent the closed-loop control system. At each time the required effect-site concentration is calculated by the controller. This value is sent to an additional algorithm taking the safety limits into account. The result of these calculations is the required effect-site concentration sent to the TCI algorithm, which steers a pump injecting propofol to the patient. The measured BIS is used as the input of the closedloop controller. The dotted lines represent the Bayesian sigmoid $E_{\max }$ model estimator. The estimator receives a priori information from the population sigmoid $E_{\max }$ model, the optimal Bayesian variances for control and the patient measured BIS values (from De Smet T, Struys MM, Greenwald S, Mortier EP, Shafer SL: "Estimation of optimal modeling weights for a Bayesian-based closed-loop system for propofol administration using the bispectral index as a controlled variable: a simulation study. Anesth Analg 2007; 105:1629-1638, with permission) 


\section{Conclusion}

Closed-loop drug delivery in anesthesia is certainly feasible. Unfortunately, most of the described closed-loop technologies have been used under well-controlled research conditions. The challenge is now to prove fully the safety and utility for its adaption into clinical practice [92]. Finally, clinicians will have to determine whether or not, adaptive, intelligent computer systems with dual, interacting, closed-loop systems will facilitate better control and improve outcome [3•].

Acknowledgments M.M.R.F. Struys is supported by a grant from IWT-Flanders for developing closed-loop in collaboration with the Ghent University Department of Engineering, and has grants pending with ECC for closed-loop development.

Disclosure M.M. Neckebroek: none; T. De Smet: none; M.M.R.F. Struys: received compensation from British Journal of Anaesthesia for serving as a board member. The Ghent University holds patent rights on the Bayesian closed-loop controller for propofol administration, described in this article.

\section{References}

Papers of particular interest, published recently, have been highlighted as:

- Of importance

•- Of major importance

1. Kissin I. General anesthetic action: an obsolete notion? [editorial]. Anesth Analg. 1993;76:215-8.

2. Åström KJ, Murray RM. Feedback Systems : An introduction for scientists and engineers. Princeton: Princeton University Press; 2008.

3. - Absalom AR, De Keyser R, Struys MM. Closed loop anesthesia: are we getting close to finding the holy grail? Anesth Analg. 2011;112:516-8. Interesting editorial describing the challenges for closed-loop drug administration.

4. O'Hara DA, Bogen DK, Noordergraaf A. The use of computers for controlling the delivery of anesthesia. Anesthesiology. 1992;77:563-81.

5. Verkaaik AP, Van Dijk G. High flow closed circuit anaesthesia. Anaesth Intensive Care. 1994;22:426-34.

6. el-Attar AM. Guided isoflurane injection in a totally closed circuit. Anaesthesia. 1991;46:1059-63.

7. Struys MM, Kalmar AF, De Baerdemaeker LE, Mortier EP, Rolly G, Manigel J, Buschke W. Time course of inhaled anaesthetic drug delivery using a new multifunctional closed-circuit anaesthesia ventilator. In vitro comparison with a classical anaesthesia machine. Br J Anaesth. 2005;94:306-17.

8. Miekisch W, Fuchs P, Kamysek S, Neumann C, Schubert JK. Assessment of propofol concentrations in human breath and blood by means of HS-SPME-GC-MS. Clin Chim Acta. 2008;395:32-7.

9. Grossherr M, Hengstenberg A, Meier T, Dibbelt L, Igl BW, Ziegler A, Schmucker P, Gehring H. Propofol concentration in exhaled air and arterial plasma in mechanically ventilated patients undergoing cardiac surgery. Br J Anaesth. 2009;102:608-13.

10. Schüttler J, Schwilden H. Closed-loop systems in clinical practice. Curr Opin Anesth. 1997;9:457-61.

11. Vanluchene AL, Vereecke H, Thas O, Mortier EP, Shafer SL, Struys MM. Spectral entropy as an electroencephalographic measure of anesthetic drug effect: a comparison with bispectral index and processed midlatency auditory evoked response. Anesthesiology. 2004;101:34-42.

12. Vanluchene AL, Struys MM, Heyse BE, Mortier EP. Spectral entropy measurement of patient responsiveness during propofol and remifentanil. A comparison with the bispectral index. Br J Anaesth. 2004;93:645-54.

13. - Liu N, Le Guen M, Benabbes-Lambert F, Chazot T, Trillat B, Sessler DI, Fischler M. Feasibility of closed-loop titration of propofol and remifentanil guided by the spectral M-Entropy monitor. Anesthesiology 2012;116:286-95. This randomized controlled trial describes automated coadministration of propofol and remifentanil, guided by M-Entropy analysis of the electroencephalogram. The authors proved their hypothesis that a novel dual-loop controller with an M-Entropy monitor increases time spent within predetermined target entropy ranges.

14. Kenny GN, Mantzaridis H. Closed-loop control of propofol anaesthesia. Br J Anaesth. 1999;83:223-8.

15. Kenny GN, Mantzaridis H, Fisher AC. Validation of anaesthetic depth by closed-loop control, memory and awareness in anaesthesia. In: Sebel P, Bonke B, Winograd E, editors. Englewood Cliffs: Prentice Hall; 1993. pp. 225-264.

16. Pilge S, Zanner R, Schneider G, Blum J, Kreuzer M, Kochs EF. Time delay of index calculation: analysis of cerebral state, bispectral, and narcotrend indices. Anesthesiology. 2006;104:488-94.

17. Mathews DM, Cirullo PM, Struys MM, De Smet T, Malik RJ, Chang CL, Neuman GG. Feasibility study for the administration of remifentanil based on the difference between response entropy and state entropy. Br J Anaesth. 2007;98:785-91.

18. • Mathews DM, Clark L, Johansen J, Matute E, Seshagiri CV. Increases in electroencephalogram and electromyogram variability are associated with an increased incidence of intraoperative somatic response. Anesth Analg. 2012;114:759-70. This study proves the correlation between increases in $s B I S$, the variability of the Bispectral Index (BIS), sEMG, the variability of facial electromyogram power (EMG), and the Composite Variability Index (CVI) and intraoperative somatic responses.

19. Struys MM, Mortier EP, De Smet T. Closed loops in anaesthesia. Best Pract Res Clin Anaesthesiol. 2006;20:211-20.

20. Bickford R. Automatic EEEG control of general anesthesia. Electroencephalogr Clin Neurophysiol. 1950;2:93-6.

21. Suppan P. Feed-back monitoring in anaesthesia. II. Pulse rate control of halothane administration. Br J Anaesth. 1972;44:1263-71.

22. Suppan P. Feed-back monitoring in anaesthesia. IV. The indirect measurement of arterial pressure and its use for the control of halothane administration. Br J Anaesth. 1977;49:141-50.

23. Lampard DG, Brown WA, Cass NM, Ng KC. Computer-controlled muscle paralysis with atracurium in the sheep. Anaesth Intensive Care. 1986;14:7-11.

24. de Vries JW, Ros HH, Booij LH. Infusion of vecuronium controlled by a closed-loop system. Br J Anaesth. 1986;58:1100-3.

25. Struys M, de Smet T. Principles of drug actions: target-controlled infusions and closed-loop administration. In: Evers AS, Maze M, Kharasch ED, editors. Anesthetic pharmacology: basic principles and clinical practice. Cambridge: Cambridge University Press, 2011. pp. 103-122.

26. Linkens DA, Asbury AJ, Rimmer SJ, Menad M. Identification and control of muscle-relaxant anaesthesia. IEEE Proc. 1982;129: $136-41$. 
27. Ritchie G, Ebert JP, Jannett TC, Kissin I, Sheppard LC. A microcomputer based controller for neuromuscular block during surgery. Ann Biomed Eng. 1985;13:3-15.

28. Jaklitsch RR, Westenskow DR, Pace NL, Streisand JB, East KA. A comparison of computer-controlled versus manual administration of vecuronium in humans. J Clin Monit. 1987;3:269-76.

29. Puri GD, Kumar B, Aveek J. Closed-loop anaesthesia delivery system (CLADS) using bispectral index: a performance assessment study. Anaesth Intensive Care. 2007;35:357-62.

30. Absalom AR, Sutcliffe N, Kenny GN. Closed-loop control of anesthesia using Bispectral index: performance assessment in patients undergoing major orthopedic surgery under combined general and regional anesthesia. Anesthesiology. 2002;96:67-73.

31. Zbinden AM, Feigenwinter P, Petersen-Felix S, Hacisalihzade S. Arterial pressure control with isoflurane using fuzzy logic. $\mathrm{Br} \mathbf{J}$ Anaesth. 1995;74:66-72.

32. Luginbuhl M, Bieniok C, Leibundgut D, Wymann R, Gentilini A, Schnider TW. Closed-loop control of mean arterial blood pressure during surgery with alfentanil: clinical evaluation of a novel model-based predictive controller. Anesthesiology. 2006;105: $462-70$.

33. - De Smet T, Struys MM, Neckebroek MM, Van den Hauwe K, Bonte S, Mortier EP. The accuracy and clinical feasibility of a new bayesian-based closed-loop control system for propofol administration using the bispectral index as a controlled variable. Anesth Analg. 2008;107:1200-10. This article introduces a newly developed Bayesian-based, patient-individualized, modelbased, adaptive control method for bispectral index (BIS) guided propofol infusion into clinical practice and compares its accuracy and clinical feasibility under direct observation of an anesthesiologist versus BIS guided, effect compartment controlled propofol administration titrated by the anesthesiologist during ambulatory gynecological procedures.

34. De Smet T, Struys MM, Greenwald S, Mortier EP, Shafer SL. Estimation of optimal modeling weights for a Bayesian-based closed-loop system for propofol administration using the bispectral index as a controlled variable: a simulation study. Anesth Analg. 2007;105:1629-38.

35. Klim S, Mortensen SB, Kristensen NR, Overgaard RV, Madsen $\mathrm{H}$. Population stochastic modelling (PSM)-an R package for mixed-effects models based on stochastic differential equations. Comput Methods Programs Biomed. 2009;94:279-89.

36. Edwards ND, Mason DG, Ross JJ. A portable self-learning fuzzy logic control system for muscle relaxation. Anaesthesia. 1998; 53:136-9.

37. Haddad WM, Bailey JM. Closed-loop control for intensive care unit sedation. Best Pract Res Clin Anaesthesiol. 2009;23:95-114.

38. Moore BL, Quasny TM, Doufas AG. Reinforcement learning versus proportional-integral-derivative control of hypnosis in a simulated intraoperative patient. Anesth Analg. 2011;112:350-9.

39. Moore BL, Doufas AG, Pyeatt LD. Reinforcement learning: a novel method for optimal control of propofol-induced hypnosis. Anesth Analg. 2011;112:360-7.

40. Sheiner LB, Beal S, Rosenberg B, Marathe VV. Forecasting individual pharmacokinetics. Clin Pharmacol Ther. 1979;26: 294-305.

41. Garraffo R, Iliadis A, Cano JP, Dellamonica P, Lapalus P. Application of Bayesian estimation for the prediction of an appropriate dosage regimen of amikacin. J Pharm Sci. 1989;78:753-7.

42. Struys MM, De Smet T, Mortier EP. Simulated drug administration: an emerging tool for teaching clinical pharmacology during anesthesiology training. Clin Pharmacol Ther. 2008;84: 170-4.

43. Sartori V, Schumacher, PM, Bouillon T, Lueginbuehl M, Morari M. On-line estimation of propofol pharmacodynamic parameters. 27th IEEE EMBS conference. Shangai, 2005, pp 1-4.
44. Gentilini A, Frei CW, Glattfelder AH, Morari M, Schnider TW. Identification and targeting ploicies for computer-controlled infusion pumps. Crit Rev Biomed Eng. 2000;28:179-85.

45. Zadeh LA. A note on prototype theory and fuzzy sets. Cognition. 1982;12:291-7.

46. Kern SE, Johnson JO, Westenskow DR. Fuzzy logic for model adaptation of a pharmacokinetic-based closed loop delivery system for pancuronium. Artif Intell Med. 1997;11:9-31.

47. Ng KF, Yuen TS, Ng VM. A comparison of postoperative cognitive function and pain relief with fentanyl or tramadol patientcontrolled analgesia. J Clin Anesth. 2006;18:205-10.

48. Beilin B, Bessler H, Papismedov L, Weinstock M, Shavit Y. Continuous physostigmine combined with morphine-based patient-controlled analgesia in the postoperative period. Acta Anaesthesiol Scand. 2005;49:78-84.

49. Sveticic G, Gentilini A, Eichenberger U, Luginbuhl M, Curatolo M. Combinations of morphine with ketamine for patient-controlled analgesia: a new optimization method. Anesthesiology. 2003;98:1195-205.

50. White I, Ghinea R, Avital S, Chazan S, Dolkart O, Weinbroum AA. Morphine at "sub-analgesic" background infusion rate plus low-dose PCA bolus control pain better and is as safe as twice a bolus-only PCA regimen: a randomized, double blind study. Pharmacol Res. 2012;66:185-91.

51. Lipszyc M, Winters E, Engelman E, Baurain M, Barvais L. Remifentanil patient-controlled analgesia effect-site target-controlled infusion compared with morphine patient-controlled analgesia for treatment of acute pain after uterine artery embolization. Br J Anaesth. 2011;106:724-31.

52. Walder B, Schafer M, Henzi I, Tramer MR. Efficacy and safety of patient-controlled opioid analgesia for acute postoperative pain. A quantitative systematic review. Acta Anaesthesiol Scand. 2001;45:795-804.

53. Cronrath P, Lynch TW, Gilson LJ, Nishida C, Sembar MC, Spencer PJ, West DF. PCA oversedation: application of Healthcare Failure Mode Effect (HFMEA) Analysis. Nurs Econ. 2011; 29:79-87.

54. Volmanen P, Akural E, Raudaskoski T, Ohtonen P, Alahuhta S. Comparison of remifentanil and nitrous oxide in labour analgesia. Acta Anaesthesiol Scand. 2005;49:453-8.

55. Volmanen P, Sarvela J, Akural EI, Raudaskoski T, Korttila K, Alahuhta S. Intravenous remifentanil vs. epidural levobupivacaine with fentanyl for pain relief in early labour: a randomised, controlled, double-blinded study. Acta Anaesthesiol Scand. 2008;52:249-55.

56. Douma MR, Verwey RA, Kam-Endtz CE, van der Linden PD, Stienstra R. Obstetric analgesia: a comparison of patient-controlled meperidine, remifentanil, and fentanyl in labour. $\mathrm{Br} \mathrm{J}$ Anaesth. 2010;104:209-15.

57. Douma MR, Middeldorp JM, Verwey RA, Dahan A, Stienstra R. A randomised comparison of intravenous remifentanil patientcontrolled analgesia with epidural ropivacaine/sufentanil during labour. Int J Obstet Anesth. 2011;20:118-23.

58. Volmanen P, Palomaki O, Ahonen J. Alternatives to neuraxial analgesia for labor. Curr Opin Anaesthesiol. 2011;24:235-41.

59. Volmanen PV, Akural EI, Raudaskoski T, Ranta P, Tekay A, Ohtonen P, Alahuhta S. Timing of intravenous patient-controlled remifentanil bolus during early labour. Acta Anaesthesiol Scand. 2011;55:486-94.

60. - Freeman LM, Bloemenkamp KW, Franssen MT, Papatsonis DN, Hajenius PJ, van Huizen ME, Bremer HA, van den Akker ES, Woiski MD, Porath MM, van Beek E, Schuitemaker N, van der Salm PC, Fong BF, Radder C, Bax CJ, Sikkema M, van den Akker-van Marle ME, van Lith JM, Lopriore E, Uildriks RJ, Struys MM, Mol BW, Dahan A, Middeldorp JM. Remifentanil patient controlled analgesia versus epidural analgesia in labour. A 
multicentre randomized controlled trial. BMC Pregnancy Childbirth 2012;12:63. Description of an ongoing large multicenter study investigating the safety of remifentanil PCA during labor.

61. Osborne GA, Rudkin GE, Jarvis DA, Young IG, Barlow J, Leppard PI. Intra-operative patient-controlled sedation and patient attitude to control. A crossover comparison of patient preference for patient- controlled propofol and propofol by continuous infusion. Anaesthesia. 1994;49:287-92.

62. Rudkin GE, Osborne GA, Finn BP, Jarvis DA, Vickers D. Intraoperative patient-controlled sedation. Comparison of patient- controlled propofol with patient-controlled midazolam. Anaesthesia. 1992;47:376-81.

63. Osborne GA, Rudkin GE, Curtis NJ, Vickers D, Craker AJ. Intraoperative patient-controlled sedation. Comparison of patientcontrolled propofol with anaesthetist-administered midazolam and fentanyl. Anaesthesia. 1991;46:553-6.

64. Murdoch JA, Kenny GN. Patient-maintained propofol sedation as premedication in day-case surgery: assessment of a target-controlled system. Br J Anaesth. 1999;82:429-31.

65. Chapman RM, Anderson K, Green J, Leitch JA, Gambhir S, Kenny GN. Evaluation of a new effect-site controlled, patientmaintained sedation system in dental patients. Anaesthesia. 2006;61:345-9.

66. Stonell CA, Leslie K, Absalom AR. Effect-site targeted patient-controlled sedation with propofol: comparison with anaesthetist administration for colonoscopy. Anaesthesia. 2006; 61:240-7.

67. Leslie K, Clavisi O, Hargrove J. Target-controlled infusion versus manually-controlled infusion of propofol for general anaesthesia or sedation in adults. Cochrane Database Syst Rev. 2008:CD006059.

68. Doufas AG, Bakhshandeh M, Bjorksten AR, Greif R, Sessler DI. A new system to target the effect-site during propofol sedation. Acta Anaesthesiol Scand. 2003;47:944-50.

69. Doufas AG, Bakhshandeh M, Bjorksten AR, Greif R, Sessler DI. Automated responsiveness test (ART) predicts loss of consciousness and adverse physiologic responses during propofol conscious sedation. Anesthesiology. 2001;94:585-92.

70. - Doufas AG, Morioka N, Mahgoub AN, Bjorksten AR, Shafer SL, Sessler DI. Automated responsiveness monitor to titrate propofol sedation. Anesth Analg. 2009;109:778-86. This study hypothesized that loss and return of response to the automated responsiveness monitor (ARM) occur at similar sedation levels in individual subjects, independent of the propofol effect titration scheme. The authors conclude that reproducible ARM dynamics in individual subjects compares favorably with clinical and electroencephalogram sedation end points and suggests that the ARM could be used as an independent instrumental guide of drug effect during propofol-only sedation.

71. Pambianco DJ, Whitten CJ, Moerman A, Struys MM, Martin JF. An assessment of computer-assisted personalized sedation: a sedation delivery system to administer propofol for gastrointestinal endoscopy. Gastrointest Endosc. 2008.

72. - Pambianco DJ, Vargo JJ, Pruitt RE, Hardi R, Martin JF. Computer-assisted personalized sedation for upper endoscopy and colonoscopy: a comparative, multicenter randomized study. Gastrointest Endosc. 2011;73:765-72. This article describes the use of the SEDASYS System, an investigational computer-assisted personalized sedation system integrating propofol delivery with patient monitoring to enable endoscopist/nurse teams to safely administer propofol. The authors conclude that the SEDASYS System could provide endoscopist/nurse teams a safe and effective on-label means to administer propofol to effect minimal to moderate sedation during routine colonoscopy and EGD.

73. Chaudhri S, Colvin JR, Todd JG, Kenny GN. Evaluation of closed loop control of arterial pressure during hypotensive anaesthesia for local resection of intraocular melanoma. Br J Anaesth. 1992;69:607-10.

74. O'Hara DA, Derbyshire GJ, Overdyk FJ, Bogen DK, Marshall BE. Closed-loop infusion of atracurium with four different anesthetic techniques. Anesthesiology. 1991;74:258-63.

75. Olkkola KT, Schwilden H, Apffelstaedt C. Model-based adaptive closed-loop feedback control of atracurium-induced neuromuscular blockade. Acta Anaesthesiol Scand. 1991;35:420-3.

76. Schwilden H, Schuttler J, Stoeckel H. Closed-loop feedback control of methohexital anesthesia by quantitative EEG analysis in humans. Anesthesiology. 1987;67:341-7.

77. Schwilden H, Stoeckel H, Schuttler J. Closed-loop feedback control of propofol anaesthesia by quantitative EEG analysis in humans [see comments]. Br J Anaesth. 1989;62:290-6.

78. Schwilden H, Stoeckel H. Closed-loop feedback controlled administration of alfentanil during alfentanil-nitrous oxide anaesthesia. Br J Anaesth. 1993;70:389-93.

79. Sakai T, Matsuki A, White PF, Giesecke AH. Use of an EEGbispectral closed-loop delivery system for administering propofol. Acta Anaesthesiol Scand. 2000;44:1007-10.

80. Leslie K, Absalom A, Kenny GN. Closed loop control of sedation for colonoscopy using the Bispectral Index. Anaesthesia. 2002; 57:693-7.

81. Liu N, Chazot T, Genty A, Landais A, Restoux A, McGee K, Laloe PA, Trillat B, Barvais L, Fischler M. Titration of propofol for anesthetic induction and maintenance guided by the bispectral index: closed-loop versus manual control: a prospective, randomized, multicenter study. Anesthesiology. 2006; 104:686-95.

82. Liu N, Chazot T, Trillat B, Pirracchio R, Law-Koune JD, Barvais L, Fischler M. Feasibility of closed-loop titration of propofol guided by the Bispectral Index for general anaesthesia induction: a prospective randomized study. Eur J Anaesthesiol. 2006;23: 465-9.

83. - Liu N, Chazot T, Hamada S, Landais A, Boichut N, Dussaussoy C, Trillat B, Beydon L, Samain E, Sessler DI, Fischler M: Closed-loop coadministration of propofol and remifentanil guided by bispectral index: a randomized multicenter study. Anesth Analg. 2011;112:546-57. This work describes the development of a proportional-integral-derivative controller allowing the closedloop coadministration of propofol and remifentanil, guided by a Bispectral Index (BIS) monitor, during induction and maintenance of general anesthesia. The controller was compared with manual target-controlled infusion. The authors conclude that the controller allows the automated delivery of propofol and remifentanil and maintains BIS values in predetermined boundaries during general anesthesia better than manual administration.

84. Looke TD. Feedback control is engineering, let's treat it as such. Anesthesiology 2012;117:678-9; author reply 679-81.

85. Mortier E, Struys M, De Smet T, Versichelen L, Rolly G. Closedloop controlled administration of propofol using bispectral analysis. Anaesthesia. 1998;53:749-54.

86. Struys MM, De Smet T, Versichelen LF, Van De Velde S, Van den Broecke R, Mortier EP. Comparison of closed-loop controlled administration of propofol using Bispectral Index as the controlled variable versus "standard practice" controlled administration. Anesthesiology. 2001;95:6-17.

87. Glass PSA, Rampil IJ. Automated Anesthesia: Fact or Fantasy ? Anesthesiology. 2001;95:1-2.

88. Struys MM, De Smet T, Greenwald S, Absalom AR, Binge S, Mortier EP. Performance evaluation of two published closed-loop control systems using bispectral index monitoring: a simulation study. Anesthesiology. 2004;100:640-7.

89. Gentilini A, Rossoni-Gerosa M, Frei CW, Wymann R, Morari M, Zbinden AM, Schnider TW. Modeling and closed-loop control of 
hypnosis by means of bispectral index (BIS) with isoflurane. IEEE Trans Biomed Eng. 2001;48:874-89.

90. Gentilini A, Schaniel C, Morari M, Bieniok C, Wymann R, Schnider T. A new paradigm for the closed-loop intraoperative administration of analgesics in humans. IEEE Trans Biomed Eng. 2002;49:289-99.

91. Ionescu CM, De Keyser R, Torrico BC, De Smet T, Struys MM, Normey-Rico JE. Robust predictive control strategy applied for propofol dosing using BIS as a controlled variable during anesthesia. IEEE Trans Biomed Eng. 2008;55: 2161-70.

92. Manberg PJ, Vozella CM, Kelley SD. Regulatory challenges facing closed-loop anesthetic drug infusion devices. Clin Pharmacol Ther. 2008;84:166-9. 